\title{
DIVERSIDADE GENÉTICA ENTRE GENÓTIPOS DE Bertholletia excelsa POR MEIO DE MARCADORES MOLECULARES ISSR
}

\author{
Aline Bueno Ramalho ${ }^{1}$, Ana Aparecida Bandini Rossi ${ }^{2 *}$, Juliana Freitas Encinas Dardengo ${ }^{3}$, \\ Kelli Évelin Müller Zortéa ${ }^{4}$, Auana Vicente Tiago ${ }^{3}$, Kellen Coutinho Martins ${ }^{3}$ \\ ${ }^{1}$ Universidade do Estado de Mato Grosso, Departamento de Engenharia Florestal, Alta Floresta, Mato Grosso, Brasil - \\ nine_ramalho@hotmail.com \\ ${ }^{2 *}$ Universidade do Estado de Mato Grosso, Departamento de Ciências Biológicas, Alta Floresta, Mato Grosso, Brasil - \\ anabanrossi@gmail.com \\ ${ }^{3}$ Universidade do Estado de Mato Grosso, Programa de Pós-graduação em Biodiversidade e Biotecnologia da Rede Bionorte, Alta Floresta, \\ Mato Grosso, Brasil -ju_kk@hotmail.com, auana_bio@hotmail.com, kellen.coutinho@hotmail.com \\ ${ }^{4}$ Universidade do Estado de Mato Grosso, Programa de Pós-Graduação em Genética e Melhoramento de Plantas, Alta Floresta, Mato Grosso, \\ Brasil - kellimuller@hotmail.com
}

Recebido para publicação: 01/07/2015 - Aceito para publicação: 08/04/2016

\begin{abstract}
Resumo
A castanha-do-brasil pertence à família Lecythidaceae e é uma espécie nativa da Floresta Amazônica com elevado potencial econômico. O presente estudo objetivou avaliar a diversidade genética de genótipos de Bertholletia excelsa Bonpl. com ocorrência natural no norte do estado de Mato Grosso, com marcador molecular ISSR. Para tanto foram caracterizados 37 genótipos provenientes do município de Alta Floresta, MT, com oito primers com total de 52 locos amplificados em todos os genótipos, sendo 46 polimórficos. O número de fragmentos amplificados por primer variou de $5\left[\mathrm{Di}(\mathrm{AG})_{8} \mathrm{C}\right]$ a $8\left[\mathrm{Di}(\mathrm{GA})_{8} \mathrm{YT}\right]$ e $\left[\mathrm{Di}(\mathrm{CT})_{8} \mathrm{RC}\right]$, com média de 6 fragmentos por primer revelando um percentual médio de 88,6\% de polimorfismo. O Conteúdo de Informação Polimórfica (PIC) para cada marcador apresentou variação de 0,22 [Di(GA) $\left.{ }_{8} \mathrm{YG}\right]$ a 0,66 [Di(AG) $\left.{ }_{8} \mathrm{~T}\right]$, com média de 0,46. O método de agrupamento de Tocher e o dendrograma (UPGMA), obtido a partir das 52 bandas ISSR amplificadas, revelaram seis grupos bem definidos, confirmando uma significativa diferenciação genética entre os genótipos avaliados. Os indivíduos mais similares foram 3 e 4. Os indivíduos 12, 29 e 37 foram os mais divergentes podendo ser usados como genitores para formação de híbridos em programas de melhoramento da espécie. Recomenda-se a conservação in situ dos genótipos analisados.

Palavras-chave: Castanha-do-Br asil, Amazônia, polimorfismo.
\end{abstract}

\begin{abstract}
Genetic diversity among Bertholletia excelsa Bonpl genotypes using ISSR molecular markers. The Brazil nut belongs to Lecythidaceae family and is a native species from the Amazon rainforest with high economic potential. This study aimed to evaluate the genetic diversity among Bertholletia excelsa Bonpl genotypes and with naturally occurring in the northern State of Mato Grosso, with ISSR molecular marker. Therefore, we characterized 37 genotypes through eight primers, with a total of 52 amplified loci in all genotypes, being 46 polymorphic. The number of fragments amplified by primer ranged from $5\left[\mathrm{Di}(\mathrm{AG})_{8} \mathrm{C}\right]$ to $8\left[\mathrm{Di}(\mathrm{GA})_{8} \mathrm{YT}\right]$ and $\left[\mathrm{Di}(\mathrm{CT})_{8} \mathrm{RC}\right]$, averaging 6 fragments per primer and revealing an average percentage of $88.6 \%$ polymorphism. The Polymorphic Information Content (PIC) for each marker varied to 0.22 [Di(GA) $\left.{ }_{8} \mathrm{YG}\right]$ from $0.66\left[\mathrm{Di}(\mathrm{AG})_{8} \mathrm{~T}\right]$, with average of 0.46 . The Tocher grouping method and the dendrogram (UPGMA), obtained from 52 ISSR amplified bands revealed six well defined groups, confirming a significant genetic differentiation between the genotypes. The most similar individuals were 3 and 4. Individuals 12, 29 and 37 were the most divergent and can be used as parents for hybrid formation in the improvement programs. It is recommended to in situ conservation of analyzed genotypes.

Keywords: Brazil nut, Amazon, polymorphism.
\end{abstract}

\section{INTRODUÇÃO}

A intensificação das atividades socioeconômicas, aliada às práticas inadequadas de manejo dos recursos florestais, tem ocasionado à degradação das florestas, resultando em perda de biodiversidade e alterações no ciclo hidrológico, colaborando assim com as mudanças no clima (ANGELO et al., 2013). O desflorestamento resultante da extração intensa dos recursos madeireiros e das mudanças no uso da terra, para cultivos anuais e pastagens, tem exercido fortes pressões sobre os produtos florestais não madeireiros, particularmente sobre a castanha-do-brasil (Bertholletia excelsa Bonpl.) (HOMMA et al., 1996).

FLORESTA, Curitiba, PR, v. 46, n. 2, p. 207 - 214, abr. / jun. 2016.

Ramalho, A. B. et al.

ISSN eletrônico 1982-4688

DOI: $10.5380 /$ rf.v46i2.41970 
A castanha-do-brasil, pertencente à família Lecythidaceae, ocorre em terra firme de todo o território Amazônico, sendo considerada uma das espécies de maior valor da floresta amazônica tratando-se de um produto de importância econômica internacional (CAMARGO, 2010). No Brasil, a espécie ocorre nos estados do Pará, Amazonas, Acre, Maranhão, Rondônia, Mato Grosso, Amapá e Roraima (LORENZI, 2000). A diversidade genética da espécie ao longo da Amazônia é extremamente baixa e sua distribuição geográfica ampla em comparação com espécies próximas do gênero Lecythis spp., o que sugere uma dispersão recente da espécie que provavelmente não poderia ser atribuída somente a dispersores não humanos (SHEPARD JR.; RAMIREZ, 2011).

A coleta dos frutos de castanha-do-brasil é realizada nos meses de novembro a março, a partir de uma prática que sobrevive há décadas, "o extrativismo de coleta". Dentre os poucos animais capazes de abrir os frutos, destaca-se a cutia (Dasyprocta spp.), que além de ser o principal predador, é também o principal dispersor não humano da castanha (YANG, 2009).

Em decorrência da pressão de exploração da castanha-do-brasil e da fragmentação dos habitats onde a espécie ocorre naturalmente, as análises genéticas tornam-se de grande importância, já que o conhecimento gerado por estudos de estrutura genética de populações é fundamental para a realização de programas de conservação, gerando dados úteis na definição de áreas de conservação e mostrando as áreas com prioridades para o manejo dos recursos genéticos. Nesse sentido, os marcadores moleculares ISSR, têm auxiliado no estudo genético de populações florestais amazônicas, como em Mauritia flexuosa L. f. (ROSSI et al., 2014), Theobroma speciosum Willd. ex Spreng (GIUSTINA et al., 2014) e Theobroma subincanum Mart. (RIVAS et al., 2013).

Os marcadores moleculares são ferramentas básicas para os estudos em genética da conservação, uma vez que permitem a caracterização da variabilidade e estrutura genética nas populações. A estrutura genética da população refere-se à heterogeneidade na distribuição dos genótipos e da variabilidade genética dentro e entre as populações, a fim de se descrever como essa informação pode ser útil para a conservação e o manejo das espécies (KAMADA et al., 2009). Entre os marcadores moleculares baseados na técnica de Reação de Polimerização em Cadeia (PCR), o método de sequências simples repetidas (ISSR) é amplamente utilizado em estudos de diversidade e variabilidade genética por não necessitar de informação prévia da sequência de DNA, os procedimentos laboratoriais podem ser transferidos para qualquer espécie de planta (SOUZA et al., 2005), além disso, esta técnica pode resultar em elevado grau de polimorfismo, apresentar alta reprodutibilidade e ter baixo custo (BRAGA, 2013).

Neste contexto, o presente estudo objetivou avaliar a diversidade genética de genótipos de $B$. excelsa com ocorrência natural no norte do estado de Mato Grosso, fazendo uso do marcador molecular ISSR.

\section{MATERIAL E MÉTODOS}

\section{Área de estudo}

O estudo foi realizado no município de Alta Floresta no extremo norte do estado de Mato Grosso. Alta Floresta está localizada no extremo norte do estado de Mato Grosso, com altitude média de $320 \mathrm{~m}$. O clima predominante é do tipo AWI - classificação Köppen, Clima Tropical chuvoso com nítida estação seca e com temperaturas entre 20 a $38^{\circ} \mathrm{C}$, tendo em média $26^{\circ} \mathrm{C}$. O município apresenta um clima quente e úmido com quatro meses de estiagem, iniciando em meados do mês de maio e prolongando-se até meados de setembro, cuja principal característica é a frequência de temperaturas elevadas, podendo atingir nos seus dias mais quentes, temperaturas superiores a $40{ }^{\circ} \mathrm{C}$ (FERREIRA, 2001).

\section{Material Vegetal}

Foram selecionados trinta e sete indivíduos adultos de $B$. excelsa com ocorrência natural em pastagens no município de Alta Floresta, MT, localizados na MT-325 e MT-208, com distância mínima de 50 m entre sí. Destes foram coletadas folhas com auxílio de uma atiradeira manual. O material foliar foi desidratado em sílica gel e acondicionado em sacos plásticos tipo ziploc.

Em seguida, o material foi transportado para o Laboratório de Genética Vegetal e Biologia Molecular do Campus Universitário de Alta Floresta, onde foi armazenado em freezer a $-20{ }^{\circ} \mathrm{C}$ até o momento da análise.

\section{Extração do DNA total}

O DNA genômico total foi extraído seguindo o método CTAB descrito por Doyle \& Doyle (1987) com modificações: aumento da concentração de Polivinilpirrolidona (PVP) de $1 \%$ para $2 \%$ e de $\beta$-mercaptoetanol de $0,2 \%$ para $1,8 \%$ no tampão de extração, além da redução do tempo de incubação em banho-maria a $65^{\circ} \mathrm{C}$ de 60 minutos para 5 minutos. 
Foram realizados testes para amplificação inicial via PCR com DNA de dois indivíduos, a partir dos quais selecionou-se os primers de ISSR que produziram maior número de bandas confiáveis e polimorfismo reproduzível nas amostras para as análises definitivas em todos os indivíduos amostrados.

As amplificações foram realizadas em um volume total de $20 \mu \mathrm{L}$ contendo: $10 \mathrm{nM}$ Tris-HCL(pH 8.3); $50 \mathrm{mM}$ KCL; $0,1 \%$ de tween $20 ; 2,5 \mathrm{mM} \mathrm{MgCL}_{2} ; 0,2 \mathrm{mM}$ de cada dNTP; 0,2 mM de primer; 0,75 U de Taq DNA polimerase $(5 \mathrm{U} / \mu \mathrm{l}) ; 2 \%$ formamida; aproximadamente $30 \mathrm{ng}$ de DNA template e água destilada autoclavada. As amplificações foram conduzidas em termociclador MJ 96 (Biocycler) com a seguinte programação: 1 ciclo inicial de desnaturação a $94{ }^{\circ} \mathrm{C}$ por 5 minutos, seguido por 35 ciclos de $94{ }^{\circ} \mathrm{C}$ por 45 segundos, $45-53^{\circ} \mathrm{C}$ (dependendo do primer utilizado) por 45 segundos e $72{ }^{\circ} \mathrm{C}$ por 90 segundos e ciclo de extensão final de $72{ }^{\circ} \mathrm{C}$ por 7 minutos.

Os produtos de amplificação foram separados por eletroforese em gel de agarose 1,5\% em tampão corrida TBE 1X, em voltagem constante de $110 \mathrm{v}$ por 4 horas. A coloração foi feita com brometo de etídio $1 \mathrm{ng} / \mathrm{mL}$. A visualização do DNA genômico foi realizada no Transluminador de luz UVB LTB-21 x 26 (Loccus Biotecnologia) e a fotodocumentação por câmera digital (Sony).

\section{Análise de dados}

Os produtos amplificados foram designados como um único caráter, no qual a presença foi representada por "1" e a ausência por "0". Os marcadores ISSR foram então convertidos em uma matriz binominal (0/1). Como o marcador ISSR é dominante, assumiu-se que cada banda representa o fenótipo em um loco bi-alélico (GOMES et al., 2011).

A similaridade genética (sgij) entre os genótipos foi estimada utilizando o coeficiente de Jaccard, por meio da expressão:

$$
\text { sgij }=\frac{a}{a+b+c}
$$

em que: "a" presença de banda no par de genótipos; "b" presença no genótipo i e ausência em j; "c" ausência no genótipo i e presença em j, resultando em uma matriz.

A matriz de distâncias gerada pelo coeficiente aritmético do Índice de Jaccard também foi utilizada para o agrupamento dos genótipos pelo método de otimização de Tocher e pelo Método de agrupamento Médio Entre Grupos (UPGMA). As matrizes de dissimilaridade geradas e os agrupamentos foram computados com o auxílio do programa Genes ${ }^{\circledR}$ (CRUZ, 2013).

A diversidade genética do loco foi estimada com base no Índice de Conteúdo Polimórfico (PIC) que é uma estimativa utilizada para a avaliação do poder discriminatório de um loco. A informatividade do loco $p_{i}$ é a frequência do alelo $p$ no loco $p_{i}$, calculado pela equação: $P I C=1-\sum i p i^{2}$; e a informatividade do primer $p_{i j}$ é a frequência do alelo $p$ do loco $i$, no primer $j$, sendo calculada pela equação: ${ }_{\text {PICprimer }=1-\sum i^{*} \sum j p i j{ }^{2}}(\operatorname{REZENDE~} e t$ al., 2009).

\section{RESULTADOS E DISCUSSÃO}

Os oito primers de ISSR utilizados apresentaram um padrão de amplificação com bandas nítidas e bem definidas, como exemplo destaca-se a amplificação de 20 genótipos de $B$. excelsa com o primer $\operatorname{Di}(\mathrm{AG})_{8} \mathrm{C}$ na figura 1.

Conforme a tabela 1 foi amplificado um total de 52 fragmentos, sendo 46 polimórficos. O número de fragmentos amplificados por primer variou de $5\left[\mathrm{Di}(\mathrm{AG})_{8} \mathrm{~T}\right]$ a $8\left[\mathrm{Di}(\mathrm{GA})_{8} \mathrm{YT}\right]$ e $\left[\mathrm{Di}(\mathrm{CT})_{8} \mathrm{RC}\right]$, com média de 6 bandas por primer. Os oito primers de ISSR revelaram um percentual médio de 88,6\% de polimorfismo nos 37 genótipos de $B$. excelsa avaliados, sendo que os primers $\mathrm{Di}(\mathrm{AG})_{8} \mathrm{C}$ e $\mathrm{Di}(\mathrm{CT})_{8} \mathrm{RC}$ revelaram $100 \%$ de polimorfismo, enquanto que o primer $\mathrm{Di}(\mathrm{GA})_{8} \mathrm{YG}$ revelou o menor percentual $(71,4 \%)$. Santana et al. (2011) encontraram resultados semelhantes ao avaliarem acessos de Spondias sp. com marcadores moleculares ISSR, com $80 \%$ de polimorfismo e uma média de 8 bandas polimórficas por primer.

De acordo com Esselman et al. (1999), os marcadores ISSR possuem a vantagem de gerar grande quantidade de bandas, sendo abundante ao longo do genoma de eucariontes, são bastante úteis na avaliação de populações em estudos genéticos, na detecção da diversidade genética e em estudos de mapeamento genético. Os marcadores moleculares ISSRs detectaram polimorfismo e se mostraram reproduzíveis para B. excelsa, dessa forma, é um método eficiente para a detecção da variabilidade genética entre os seus genótipos. 


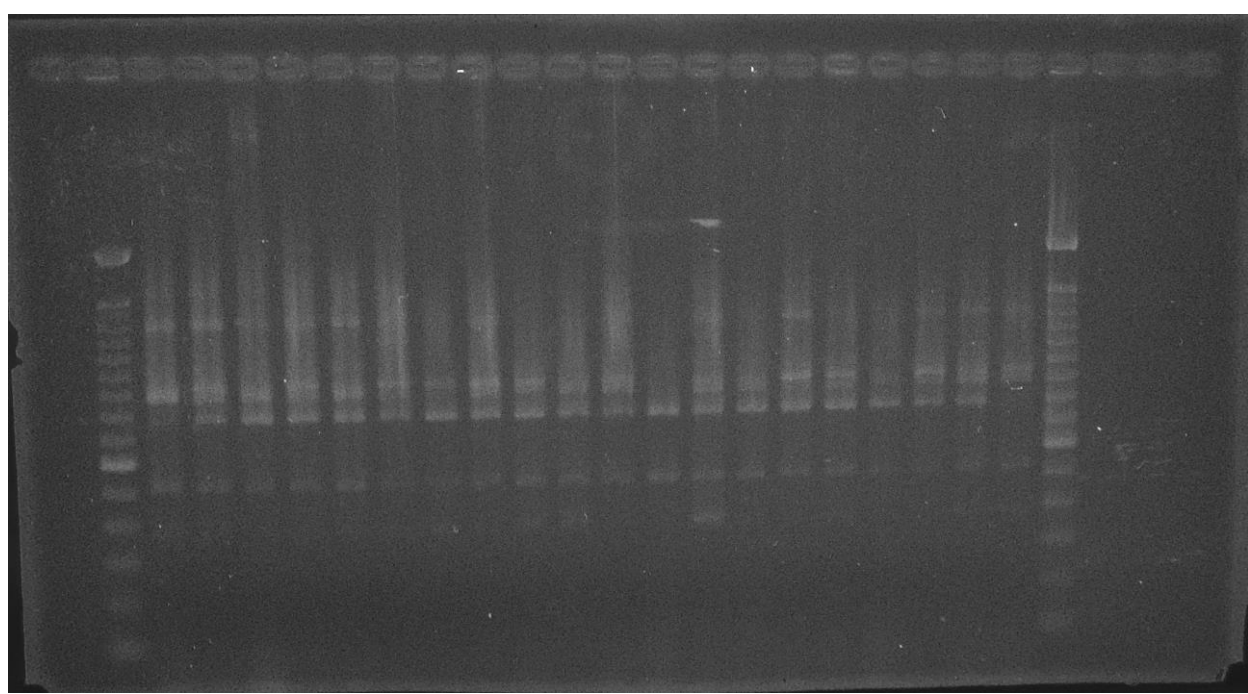

Figura 1. Padrão de amplificação dos 20 genótipos de $B$. excelsa com o primer $\operatorname{Di}(\mathrm{AG})_{8} \mathrm{~T}$.

Figure 1. Standard amplification of the 20 genotypes of $B$. excelsa with the primer $\operatorname{Di}(\mathrm{AG})_{8} \mathrm{~T}$.

Tabela 1. Marcadores ISSR utilizados na amplificação de genótipos de B. excelsa, com suas respectivas sequências, número total de bandas amplificadas (NTB), número de bandas polimórficas (NBP), percentagem de polimorfismo (\% P) e Conteúdo de Informação Polimórfica (PIC).

Table 1. ISSR markers used in the amplification of $B$. excelsa genotypes, with their respective sequence, the total number of amplified bands (NTB), number of polymorphic bands (NBP), polymorphism percentage (\% P) and Polymorphic Information Content (PIC).

\begin{tabular}{|c|c|c|c|c|c|}
\hline Primers $\left(5^{\prime}-3^{\prime}\right)$ & Sequência do primer $\left(5^{\prime}-3^{\prime}\right)$ & NTB & NBP & $\% \mathbf{P}$ & PIC \\
\hline $\mathrm{Di}(\mathrm{AG})_{8} \mathrm{~T}$ & AGAGAGAGAGAGAGAGT & 06 & 05 & 83,3 & 0,66 \\
\hline $\operatorname{Di}(\mathrm{AG})_{8} \mathrm{C}$ & AGAGAGAGAGAGAGAGC & 05 & 05 & 100 & 0,43 \\
\hline $\mathrm{Di}(\mathrm{CA})_{8} \mathrm{G}$ & CACACACACACACACAG & 06 & 05 & 83,3 & 0,42 \\
\hline $\operatorname{Di}(\mathrm{AC})_{8} \mathrm{G}$ & ACACACACACACACACG & 06 & 05 & 83,3 & 0,61 \\
\hline $\mathrm{Di}(\mathrm{AG})_{8} \mathrm{YT}$ & AGAGAGAGAGAGAGAGYT & 06 & 06 & 100 & 0,49 \\
\hline $\mathrm{Di}(\mathrm{GA})_{8} \mathrm{YT}$ & GAGAGAGAGAGAGAGAYT & 08 & 07 & 87,5 & 0,37 \\
\hline $\mathrm{Di}(\mathrm{GA})_{8} \mathrm{YG}$ & GAGAGAGAGAGAGAGAYG & 07 & 05 & 71,4 & 0,22 \\
\hline $\mathrm{Di}(\mathrm{CT})_{8} \mathrm{RC}$ & CTCTCTCTCTCTCTCTRC & 08 & 08 & 100 & 0,60 \\
\hline Total & & 52 & 46 & & \\
\hline Média & & 6 & 5 & 88,6 & 0,46 \\
\hline
\end{tabular}

O Conteúdo de Informação Polimórfica (PIC) apresentou variação de 0,22 [Di(GA) $\left.{ }_{8} \mathrm{YG}\right]$ a 0,66 $\left[\mathrm{Di}(\mathrm{AG})_{8} \mathrm{~T}\right]$, com média de 0,46 . Os primers $\mathrm{Di}(\mathrm{AG})_{8} \mathrm{~T}$, $\mathrm{Di}(\mathrm{AC})_{8} \mathrm{G}$ e $\mathrm{Di}(\mathrm{AC})_{8} \mathrm{G}$ demonstraram maiores valores de PIC com 0,66; 0,61 e 0,60, respectivamente (Tabela 1). Segundo a classificação de Botstein et al. (1980), marcadores com valores de PIC inferiores a 0,25 são pouco informativos, com valores entre 0,25 e 0,50 mediamente informativos e com valores superiores a 0,5 são considerados muito informativos. Assim, dos oito marcadores utilizados neste estudo para $B$. excelsa três foram considerados muito informativos [Di(AG) $)_{8} \mathrm{~T}$, $\mathrm{Di}(\mathrm{AC})_{8} \mathrm{G}$ e $\left.\mathrm{Di}(\mathrm{CT})_{8} \mathrm{RC}\right]$, quatro marcadores foram classificados como mediamente informativos $\left[\mathrm{Di}(\mathrm{AG})_{8} \mathrm{C}\right.$, $\left.\mathrm{Di}(\mathrm{CA})_{8} \mathrm{G}, \mathrm{Di}(\mathrm{AG})_{8} \mathrm{YT}, \mathrm{Di}(\mathrm{GA})_{8} \mathrm{YT}\right]$, e o marcador $\mathrm{Di}(\mathrm{GA})_{8} \mathrm{YG}$ foi considerado pouco informativo. Portanto, com base no PIC, recomenda-se o uso dos marcadores considerados como informativos para novos estudos de diversidade genética em $B$. excelsa.

O método de agrupamento de Tocher possibilitou a formação de seis grupos a partir das bandas geradas pelo marcador ISSR (Tabela 2 ). A maioria dos genótipos $(78,4 \%)$ foi alocada no grupo I, o grupo II e III foi formado por dois e três genótipos respectivamente, sendo que os grupos IV, V e VI foram constituídos por apenas um genótipo.

Por utilizar um critério global de agrupamento, este método tem a característica de formar grupos com apenas um genótipo cada, no caso dos genótipos com maior dissimilaridade como neste estudo, onde os indivíduos 37, 12 e 29 apresentaram-se isolados em grupos distintos, sendo, portanto considerados os indivíduos mais dissimilares (VASCONCELOS et al., 2007). 
Tabela 2. Agrupamento de 37 genótipos de B. excelsa, oriundos de populações nativas da Amazônia Matogrossense, obtido pelo método de Tocher, utilizando índice de Jaccard como medida de dissimilaridade, Alta Floresta, MT.

Table 2. Grouping of 37 genotypes of B. excelsa, coming from native populations of Mato Grosso Amazon, obtained by Tocher method, using Jaccard index as a measure of dissimilarity, Alta Floresta, MT.

\begin{tabular}{|c|c|}
\hline Grupos & Genótipos \\
\hline I & $\begin{array}{lllllllllllllllllllllllllll}3 & 4 & 5 & 2 & 23 & 21 & 36 & 25 & 1 & 18 & 19 & 6 & 8 & 9 & 10 & 16 & 15 & 14 & 7 & 11 & 13 & 32 & 35 & 33 & 20 & 30 & 31 \\
26 & 28 & & & & & & & & & & & & & & & & & & & & & & & & \end{array}$ \\
\hline II & 1734 \\
\hline III & 222427 \\
\hline IV & 37 \\
\hline V & 12 \\
\hline VI & \\
\hline
\end{tabular}

O dendrograma gerado pelo método UPGMA, com o percentual de corte de $70 \%$ de dissimilaridade, evidenciou a formação de seis grupos (Figura 2), confirmando que há diferenciação genética entre os genótipos avaliados.

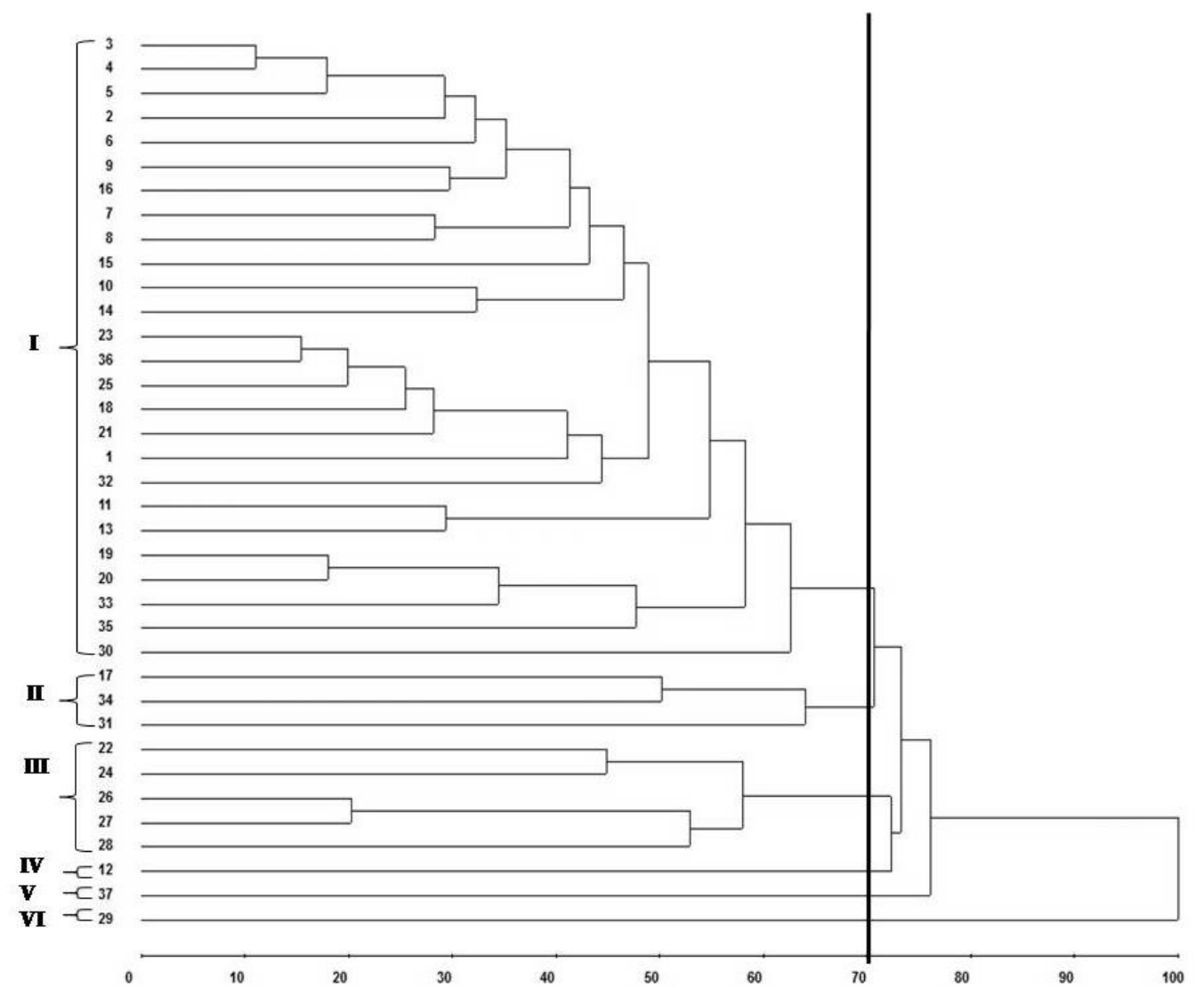

Figura 2. Dendrograma (UPGMA) baseado no coeficiente de dissimilaridade de Jaccard de 37 genótipos de $B$. excelsa de populações nativas da Amazônia Matogrossense, Alta Floresta, MT, 2015. Grupos: I, II, III, IV, V e VI.

Figure 2. Dendrogram (UPGMA) based on the dissimilarity coefficient of Jaccard of 37 genotypes of $B$. excelsa native populations of the Mato Grosso Amazon, Alta Floresta, MT, 2015. Groups: I, II, III, IV, V and VI.

Os dois métodos de agrupamento (UPGMA e Tocher) revelaram similaridades na constituição dos grupos entre os 37 genótipos. O grupo I foi representado por 25 indivíduos (70,3\%) no agrupamento UPGMA, e no método de Tocher 29 indivíduos $(78,4 \%)$, portanto a maioria dos indivíduos ficou alocada no grupo I em ambos os métodos. 
O grupo II do agrupamento UPGMA, apresentou três indivíduos (17, 34 e 31), os indivíduos 17 e 34 são similares e também foram encontrados no grupo II pelo método de Tocher. O indivíduo 31 foi mais dissimilar no grupo II pelo agrupamento UPGMA e apresentou-se no grupo I pelo método de Tocher.

O grupo III alocou 5 indivíduos $(22,24,26,27,28)$ pelo agrupamento UPGMA, os indivíduos 22, 24 e 27 também foram encontrados no grupo III pelo método de Tocher, porém com exceção dos indivíduos 26 e 28 que ficaram alocados no grupo I.

Os indivíduos 12, 37 e 29 foram os mais dissimilares segundo o agrupamento UPGMA, sendo comprovado pelo método de Tocher, que estes acessos se alocaram em grupos isolados (Grupo IV = 12) (Grupo $\mathrm{V}=37$ ) (Grupo VI =29), enquanto os indivíduos mais similares foram o 3 e 4 alocados no grupo I (Figura 2).

Estimativas das relações genéticas entre os genótipos são úteis na seleção de combinações parentais (ALI et al., 2008). Por existir variabilidade genética entre os genótipos analisados e não haver indivíduos idênticos, todos podem ser usados como fonte para bancos de germoplasma e devem ser preservados, porém prioriza-se o uso dos indivíduos mais dissimilares, que neste estudo foram os genótipos 12, 29 e 37 . Estes genótipos de $B$. excelsa podem constituir bons genitores a fim de formar combinações híbridas e maximizar programas de melhoramento da castanha-do-brasil.

A conservação in situ é uma estratégia importante para a espécie, devido ela se encontrar em extinção. Indivíduos isolados em meio às pastagens e que possuem o fluxo gênico prejudicado pela fragmentação podem ser utilizados para enxertia. Métodos de enxertia de castanha-do-brasil têm sido desenvolvidos com sucesso pela EMBRAPA desde 1980 (MOREIRA, 1994; MÜLLER, 1982). Dessa forma, na coleta de germoplasma abrangem-se as sementes para produção de mudas e gemas para execução enxertos.

Os resultados sugerem que os marcadores ISSR podem ser utilizados como uma ferramenta para a identificação de genótipos mais divergentes e assim auxiliar programas de coletas de recursos genéticos vegetais.

Os métodos de otimização de Tocher e de hierarquização UPGMA são normalmente empregados em conjunto, para complementar os resultados e auxiliar em uma melhor distinção dos agrupamentos formados. $\mathrm{O}$ emprego de mais de um método de agrupamento, em razão das diferenças na hierarquização, otimização e ordenação dos grupos, permite que a classificação deles se complemente em função dos critérios que cada técnica utiliza, e impede que inferências errôneas sejam adotadas na alocação de elementos, dentro de um determinado subgrupo de genótipos (ARRIEL et al., 2006).

\section{CONCLUSÕES}

- Os marcadores ISSR detectaram polimorfismo entre os genótipos de B. excelsa com ocorrência natural na Amazônia Matogrossense e os dois métodos de agrupamento (UPGMA e Tocher) revelaram diversidade genética entre os genótipos avaliados e indicaram os mais dissimilares.

- Os indivíduos 12, 29 e 37 foram os mais divergentes, sendo, portanto priorizados na coleta de germoplasma e para uso em futuros programas de melhoramento.

- Por haver diversidade genética entre todos os genótipos avaliados recomenda-se a conservação in situ, uma vez que a espécie $B$. excelsa encontra-se ameaçada de extinção.

- Os genótipos que se encontram isolados nas pastagens e possuem fluxo gênico prejudicado podem ser utilizados em programas de enxertia de B. excelsa.

\section{AGRADECIMENTOS}

A FAPEMAT pelo financiamento do Projeto: Estratégias de Conservação, Sustentabilidade e Manejo de Bertholletia excelsa Bonpl. (Lecythidaceae) uma Espécie Tropical da Amazônia. PROCESSO $\mathrm{N}^{\mathrm{o}}$.002.0279/2007.

\section{REFERÊNCIAS}

ALI, M. L.; RAJEWSKI, J. F.; BAENZIGER, P. S., GILL, K. S.; ESKRIDGE, K. M. Assessment of genetic diversity and relationship among a collection of US sweet sorghum germplasm by SSR markers. Molecular Breeding, v. 21, p. 497 - 509, 2008.

ANGElO, H.; POMPERMAYER, R. S.; ALMEIDA, A. N.; MOREIRA, J. M. M. Á. P. O Custo Social do Desmatamento da Amazônia Brasileira: O Caso da Castanha-do-Brasil (Bertholletia excelsa). Ciência Florestal, Santa Maria, v. 23, n. 1, p. 183 - 191, 2013.

ARRIEL, N. H. C.; MAURO, A. O. D.; MAURO, S. M. Z. D.; BAKKE, O. A.; UNÊDA-TREVISOLI, S. H.; 
COSTA, M. M.; CAPELOTO, A.; CORRADO, A. R. Técnicas multivariadas na determinação da diversidade genética em gergelim usando marcadores RAPD. Pesquisa Agropecuária Brasileira, Brasília, v. 41, n. 5, p. $801-809,2006$.

BRAGA, I. Discriminação varietal de cultivares em Urochloa brizantha por marcador molecular ISSR. 52 f. Dissertação (Mestrado de Agronomia) - Universidade do Oeste Paulista, Presidente Prudente, 2013.

BOTSTEIN, D.; WHITE, R. L.; SKOLMICK, H.; Davis, R. W. Construction of a genetic linkage map in man using restriction fragment lenght polymorphisn. American Journal of Human Genetics, v. 32, p. 314 - 331 , 1980.

CAMARGO, F. F. Etnoconhecimento e variabilidade genética de castanha-do-brasil (Berthollethia excelsa Humb. \& Bonpl.) em área da Amazônia matogrossense. 132 f. Dissertação (Mestrado em Ciências Florestais e Ambientais) - Universidade Federal de Mato Grosso, Cuiabá, 2010.

CRUZ, C. D. GENES - a software package for analysis in experimental statistic and quantitative genetics. Acta Scientiarum. Agronomy, v. 35, n. 3, p. 271 - 276, 2013.

DOYLE, J. J.; DOYLE, J. L. A rapid DNA isolation procedure for small amounts of fresh leaf tissue. Phytochemical Bulletin, v. 19, p. 11 - 15, 1987.

ESSELMAN, E. J.; JIANQIANG, L.; CRAWFORD, D. J.; WINDUSS, J. L.; WOLFE, A. D. Clonal diversity in the rare Calamagrostis porteri ssp. Insperata (Poaceae) : comparative results for allozymes and random amplified polymorphic DNA (RAPD) and inter simple sequence repeat (ISSR) markers. Molecular Ecology, Edinburgh, v. 8, n. 3, p. 443 - 451, 1999.

FERREIRA, J. C. V. Mato Grosso e seus Municípios. Cuiabá: Secretaria de Estado da Educação. 2001.365 p.

GIUSTINA, L. D.; LUZ, L. N.; VIEIRA, F. S.; ROSSI, F. S.; SOARES-LOPES, C. R. A.; PEREIRA, T. N. S.; ROSSI, A. A. B. Population structure and genetic diversity in natural populations of Theobroma speciosum Willd. Ex Spreng (Malvaceae). Genetics and Molecular Research, v. 13, n. 2, p. 3510-3519, 2014. DOI: http://dx.doi.org/10.4238/2014.

GOMES, L. R. P.; LOPES, M. T. G.; BENTES, J. L. S.; BARROS, W. S.; NETO, P. Q. C.; CONTIM, L. A. S. Genetic diversity in natural populations of Buriti (Mauritia flexuosa L. f.) Crop Breeding and Applied Biotechnology. v. 11, n. 3, p. 216 - 223, 2011.

HOMMA, A. K. O.; WALKER, R. T.; CARVAlHO, R. de A.; CONTO, A. J. de.; FERREIRA, C. A. P. Razões de risco e rentabilidade na destruição de recursos florestais: o caso de castanhais em lotes de colonos no Sul do Pará. Revista Econômica do Nordeste, Fortaleza, v. 27, n. 3, p. 515 - 535, 1996.

KAMADA, T.; PICOLI, E. A. T.; ALFENAS, A. C.; CRUZ, C. D.; VIEIRA, R. F.; OTONI, W. C. Diversidade genética de populações naturais de Pfaffia glomerata (Spreng.) Pedersen estimada por marcadores RAPD. Acta Scientiarum Agronomy, Maringá, v. 31, n. 3, p. 403 - 409, 2009.

LORENZI, H. Árvores Brasileiras: manual de identificação e cultivo de plantas arbóreas nativas do Brasil. v. 1 e 2. Nova Odessa, Instituto Plantarum, 2000.

MOREIRA, P. Recomendações técnicas para a formação de mudas de castanha-do-brasil (Bertholletia excelsa HBK). Rio Branco, EMBRAPA-CPAF-Acre, 1994. 25 p.

MÜLLER, C. H. Quebra de dormência da semente e enxertia de castanha-do-brasil. Belém, EMBRAPACPATU, 1982. 40 p.

REZENDE, R. K.; PAIVA, L. V.; PAIVA, R.; CHALFUN-JÚNIOR, A.; TORGA, P. P. Divergência genética entre cultivares de gérbera utilizando marcadores RAPD. Ciência Rural, v. 39, n. 8, p. 2435 - 2440, 2009.

RIVAS, L. H.; GIUSTINA, L. D.; LUZ, L. N.; KARSBURG, I. V.; PEREIRA, T. N. S.; ROSSI, A. A. B. Genetic diversity in natural populations of Theobroma subincanum Mart. in the Brazilian Amazon. Genetics and Molecular Research, v. 12, n. 4, p. 4998 - 5006, 2013.

ROSSI, F. S.; ROSSI, A. A. B.; DARDENGO, J. F. E.; BRAUWERS, L. R.; SILVA, M. L.; SEBBENN, A. M. Diversidade genética em populações naturais de Mauritia flexuosa L. f. (Arecaceae) com uso de marcadores ISSR. Science Forestry, Piracicaba, v. 42, n. 104, p. 631 - 639, 2014.

SANTANA, I. B. B.; OILVEIRA, E. J.; FILHO, W. S. S.; RITZINGER, R.; AMORIN, E. P.; COSTA, M. A. P.

FLORESTA, Curitiba, PR, v. 46, n. 2, p. 207 - 214, abr. / jun. 2016.

Ramalho, A. B. et al.

ISSN eletrônico 1982-4688

213

DOI: $10.5380 /$ rf.v46i2.41970 
C.; MOREIRA, R. F. C. Variabilidade genética entre acessos de umbu-cajazeira mediante análise de marcadores ISSR. Revista Brasileira de Fruticultura, v. 33, p. 868 - 876, 2011.

SHEPARD JR.; G. H.; RAMIREZ, H. Human dispersal of the Brazil nut (Bertholletia excelsa, Lecythidaceae) in ancient Amazonia. Economic Botany, v. 65, n. 1 p. 44 - 65, 2011.

SOUZA, V. Q.; PEREIRA, A. S.; MARINIKOPP, M.; COIMBRA, J. L. M.; CARVALHO, F. I. F.; LUZ, V. K.; OLIVEIRA, A. C. Dissimilaridade genética em mutantes da aveia tolerantes e sensíveis a ácidos orgânicos. Bragantia, Campinas, v. 64, n. 4, p. 569 - 575, 2005.

VASCONCELOS, E. S.; CRUZ, C. D.; BHERING, L. L.; RESENDE JÚNIOR, M. F. R. Método alternativo para análise de agrupamento. Pesquisa Agropecuária Brasileira, v. 42, n. 10, p. 1421 - 1428, 2007.

YANG, J. Brazil nuts and associated health benefits. LWT - Food Science and Technology, v. 42, n. 10, p. 1573 - 1580, 2009. 